Témoigner Témoigner. Entre histoire et mémoire

Getuigen Revue pluridisciplinaire de la Fondation Auschwitz

$121 \mid 2015$

Violences radicales en scène

\title{
Itsembatsemba
}

\section{Rémi Korman}

\section{OpenEdition}

\section{Journals}

\section{Édition électronique}

URL : https://journals.openedition.org/temoigner/3531

DOI : 10.4000/temoigner.3531

ISSN : 2506-6390

\section{Éditeur :}

Éditions du Centre d'études et de documentation Mémoire d'Auschwitz, Éditions Kimé

\section{Édition imprimée}

Date de publication : 1 octobre 2015

Pagination : 173-174

ISSN : 2031-4183

\section{Référence électronique}

Rémi Korman, «Itsembatsemba », Témoigner. Entre histoire et mémoire [En ligne], 121 | 2015, mis en ligne le 01 octobre 2016, consulté le 04 février 2022. URL : http://journals.openedition.org/temoigner/ 3531 ; DOI : https://doi.org/10.4000/temoigner.3531

\section{Ce document a été généré automatiquement le 4 février 2022}

Tous droits réservés 


\title{
Itsembatsemba
}

\author{
Rémi Korman
}

1 Dès les premiers massacres commis contre les Tutsi au Rwanda, un nouveau vocabulaire permettant de décrire les événements en kinyarwanda apparaît. C'est tout d'abord par la métaphore du vent (umuyaga) que sont nommées les violences anti-Tutsi de 1959 jusqu'au début des années 1990. Mais en raison de la radicalité de la violence et de la nouveauté du processus d'extermination en 1994, cet euphémisme ne suffit plus.

2 En français et en anglais, les deux autres langues nationales après 1994, le terme de génocide est immédiatement présent. Il est utilisé par tous les hommes politiques ainsi que par les intellectuels. Les débats qui émergent alors sur la dénomination en Kinyarwanda du génocide ne sont pas de simples enjeux de traduction, mais portent des enjeux politiques. Au-delà des mots, la question est de savoir quelles victimes ils désignent. Cette question de la dénomination fait l'objet de nombreuses discussions lors de la première conférence internationale sur le génocide organisée à Kigali en 1995. En accord avec la logique d'Union nationale du nouveau gouvernement, il est convenu d'accoler en une seule expression les termes génocide et massacres, traduits en kinyarwanda par Itsembabwoko n'Itsembatsemba. Itsembabwoko désigne alors le massacre d'un groupe ou d'une ethnie (du verbe gutsemba: exterminer et d'ubwoko: l'ethnie ou le groupe). Sans le nommer précisément, l'expression désigne le génocide des Tutsi. Itsembatsemba renvoie au massacre des Hutu (dits "modérés») tués pour leurs idées politiques ou en raison de leur refus de participer au génocide. À ces expressions ne nommant pas clairement les victimes pour des questions de réconciliation nationale, de nombreux rescapés préfèrent alors l'expression Itsembabatutsi (extermination des Batutsi, pluriel du mot Tutsi).

3 Bien que s'appliquant alors, au niveau politique, aux massacres commis contre les Hutu dits modérés, l'expression Itsembatsemba renvoie aussi dans l'imaginaire populaire à la volonté d'extermination des Tutsi. Dès la création en 1992 du parti extrémiste de la Coalition pour la défense de la République (CDR), un chant proclamait: Tubatsembatsembe (Exterminons-les). Dans le cadre du procès de Jean-Bosco Barayagwiza au TPIR, cette formule fut largement étudiée, considérée par le bureau du procureur comme un élément de la planification du génocide. 
4 Finalement, la fin du gouvernement de transition et l'évolution politique du Rwanda engendrent de nouvelles dénominations officielles. Au début des années 2000 , le gouvernement décide de transcrire le concept de génocide en kinyarwanda. Apparaît ainsi dans la nouvelle Constitution de 2003 l'expression de jenoside. Cette dernière est enfin remplacée en 2008 par l'expression de génocide contre les Tutsi (jenoside yakorewe abatutsi).

\section{BIBLIOGRAPHIE}

Évariste Ntakirutimana, «Les mots pour le dire et les enjeux derrière », Francophilia, Journal of Interdisciplinary Studies, Volume 1, $\mathrm{n}^{\circ} 1$, Printemps 2011, p. 49-59.

Assumpta Mugiraneza, «Les écueils dans l'appréhension de l'histoire du génocide des Tutsis », Rwanda. Quinze ans après. Penser et écrire l'histoire du génocide des Tutsis, Revue d'histoire de la Shoah, Paris, 2009, p. 153-172.

\section{AUTEUR}

\section{RÉMI KORMAN}

EHESS 